\title{
GAMBARAN KOMPATIBILITAS SEDIAAN OBAT INTRAVENA DENGAN SEDIAAN LAIN PADA PASIEN DI INTENSIVE CARE UNIT
}

\author{
Overview of the compatibility between intravenous drugs and others \\ in the Intensive Care Unit patients
}

\author{
Siti Syahbarni, Maria Caecilia Nanny Setiawati, Erna Prasetya Ningrum \\ Sekolah Tinggi Ilmu Farmasi Yayasan Pharmasi Semarang, Jawa Tengah, Indonesia
}

*) E-mail korespondensi : caecil_nanny@yahoo.co.id

\begin{abstract}
ABSTRAK
Pencampuran sediaan parenteral memiliki beberapa kekurangan, salah satunya adalah kemungkinan terjadinya inkompatibilitas obat. Inkompatibilitas adalah suatu reaksi yang tidak diinginkan yang dapat mengubah stabilitas kimia, fisika, maupun maupun terapeutik dari suatu sediaan obat. Penelitian ini bertujuan untuk mengetahui karakteristik pasien yang mendapat terapi sediaan parenteral IV dan memberikan gambaran kompatibilitas sediaan parenteral IV yang diberikan secara bersamaan pada pasien yang dirawat di ruang Intensive Care Unit Rumah Sakit di Semarang bulan Februari 2020. Penelitian ini dilakukan dengan menggunakan data rekam medis (RM). Metode penelitian yang digunakan adalah retrospektif dengan teknik sampling purposive sampling, kemudian dianalisis secara deskriptif non analitik yaitu dengan mendeskripsikan suatu keadaan secara obyektif serta melihat kesesuaian berdasarkan literatur. Hasil penelitian menunjukkan karakteristik pasien di ruang Intensive Care Unit yang mendapat terapi sediaan parenteral IV berdasarkan diagnosa dokter dan usia pasien. Kelompok diagnosa terbanyak adalah gagal napas dari berbagai kausa sebesar $41,18 \%$, sedangkan kelompok usia pasien terbanyak yang dirawat di Intensive Care Unit adalah usia >65 tahun sebesar $35,29 \%$. Gambaran kompatibilitas sediaan parenteral IV yang diberikan secara bersamaan diklasifikasikan sebagai inkompatibel (I) sebesar 3,72\%, kompatibel (K) sebesar $25,71 \%$, not clear (NC) sebesar $1,53 \%$ dan no recommendation (NR) sebesar $0,41 \%$. Hasil dari penelitian ini sebagian besar diklasifikasikan sebagai no information (NI) yaitu sebesar $68,64 \%$.
\end{abstract}

Kata kunci : Intensive Care Unit, inkompatibel, sediaan intravena

\section{ABSTRACT}

Parenteral dosage mixing has several deficiencies, one of which is the possibility of drug incompatibilities. Incompatibilities are an unwanted reaction that can alter the chemical, physical, or therapeutic stability of a dosage. This study aims to determine the characteristics of patients and give an overview of a parenteral dosage of the prescribed IV administered simultaneously in patients treated in the Intensive Care Unit of Hospital in Semarang during February 2020. This study was a retrospective descriptive research with purposive sampling, then analyzed descriptively none analytically by describing an objective state as well as seeing conformity based on literature. The results showed the characteristics of patients in Intensive Care Unit that received parenteral dosage IV therapy based on doctor's diagnosis and patient's age. The most diagnosis group was the failed breath of a variety of $41.18 \%$, while the most patient age group treated in the Intensive Care Unit was age > 65 years by $35.29 \%$. The simultaneously-administered IV parenteral dosage Overview was classified as an incompatibilities (I) of $3.72 \%$, compatible (C) amounting to $25.71 \%$, not clear (NC) amounting to $1.53 \%$ and no recommendation (NR) amounting to $0.41 \%$. The results of this study were mostly classified as no information (NI) which is $68.64 \%$.

Keywords: Intensive Care Unit, incompatibilities, intravenous drugs

\section{PENDAHULUAN}

Pasien di Intensive Care Unit (ICU) umumnya mendapatkan terapi secara intravena (IV), mengingat kondisi pasien di Intensive Care Unit berada dalam kondisi yang tidak stabil (Dwijayanti, et al., 2016). Tujuan pemberian obat secara parenteral pada pasien di Intensive Care Unit adalah memberikan efek obat yang lebih cepat dan lebih stabil sesuai dengan kondisi pasien yang mengalami penurunan kesadaran (Surahman, et al., 2008). Sediaan parenteral pada pasien Intensive Care Unit tidak jarang diberikan secara bersamaan sehingga dilakukan pencampuran sediaan parenteral (IV Admixture). Pencampuran sediaan parenteral memiliki beberapa kekurangan, salah satunya adalah kemungkinan terjadinya inkompatibilitas obat, yang dapat mengganggu stabilitas dan atau efektivitas obat yang dicampurkan (Departemen Kesehatan RI, 2009).

Medication Error pada proses pencampuran dan pemberian sediaan IV salah satunya adalah kompatibilitas. Kompatibilitas adalah suatu kondisi 
ketercampuran antara bahan obat dengan bahan obat lain atau dengan pelarut, yang dapat terjadi, baik dalam syringe, secara additive, dan atau melalui $Y$ site. Sedangkan inkompatibilitas adalah suatu reaksi yang tidak diinginkan yang dapat mengubah stabilitas kimia, fisika, maupun terapeutik dari suatu sediaan obat atau disebut kondisi tidak tercampur (RCN, 2010). Kemungkinan terjadinya inkompatibilitas dapat diperkirakan menggunakan beberapa teori, diantaranya yaitu perbedaan polaritas, reaksi asam basa, teori kesetimbangan ion Henderson-Hasselbalch, teori kelarutan. Kompatibilitas pada cairan intravena meliputi kompatibilitas dengan pelarut dan kompatibilitas dengan obat-obat lain. Persentase terjadinya kesalahan pemilihan jenis pelarut dan jumlah pelarut dilaporkan dalam sebuah penelitian di Intensive Care Unit di Tehran sebesar $12.90 \%$ dan $10.00 \%$ (Fahimi et al., 2008). Sebuah penelitian yang dilakukan di Kanada memaparkan fakta terkait yaitu ketidaktepatan pemberian obat IV secara bersamaan melalui $Y$-site yang terjadi sebesar $8.50 \%$ (Kanji et al., 2013).

Proses pencampuran yang tidak tepat berpotensi menyebabkan pengendapan sehingga kadar obat terlarut berkurang dan menyebabkan tidak optimalnya terapi sehingga dapat menyebabkan penurunan kualitas hidup pasien maupun mengancam jiwa (Lucida et al., 2014). Proses rekonstitusi dan pencampuran sediaan intravena biasanya dilakukan oleh perawat segera sebelum disuntikkan kepada pasien. Proses ini perlu diawasi oleh farmasis untuk menjamin bahwa prosedur yang dilakukan telah sesuai GPP (Good Preparation Practices).

Pengetahuan tentang profil kompatibilitas obat sangat diperlukan karena mampu mengurangi masalah pada fasilitas pelayanan kesehatan dan pasien. Penelitian terkait kompatibilitas sediaan IV di Intensive Care Unit belum pernah dilakukan di rumah sakit tempat pengambilan data. Penelitian ini bertujuan untuk melihat profil atau gambaran kompatibilitas sediaan parenteral IV diberikan bersamaan di ruang Intensive Care Unit rumah sakit tersebut guna untuk mencari peluang perbaikan pemberian pelayanan kesehatan.

\section{METODE}

Penelitian ini dilakukan dengan rancangan deskriptif observasional. Teknik sampling yang digunakan dalam penelitian ini adalah purposive sampling. Penelitian ini dilakukan di ruang Intensive Care Unit SMC RS Telogorejo Semarang setelah mendapat persetujuan dari pihak rumah sakit dengan nomor Ethical Clearance (No.10213/TU.710/KEPK/K/202).

Sampel yang digunakan pada penelitian ini adalah keseluruhan populasi, total pasien yang pernah dirawat di Intensive Care Unit selama bulan Februari 2020 sebanyak 79 pasien. Pasien yang sesuai dengan kriteria inklusi sebanyak 68 pasien dan sisanya termasuk kriteria eksklusi, yaitu sebanyak 11 pasien yang hanya menerima satu macam sediaan obat parenteral IV. Data yang sudah diperoleh kemudian dianalisis secara deskriptif meliputi karakteristik pasien berdasarkan diagnosa dan usia pasien serta melihat gambaran kompatibilitas sediaan parenteral IV yang diberikan secara bersamaan pada pasien yang dirawat di Intensive Care Unit selama Februari 2020. Hasil analisis campuran obat IV diklasifikasikan menjadi: kompatibel (K), inkompatibel (I), no information (NI), not clear (NC) dan no recommendation (NR). Acuan yang digunakan dalam melakukan klasifikasi suatu campuran dalam penelitian ini adalah Injectable Drugs Guide, Handbook on Injectable Drugs, Medscape dan jurnal penelitian.

Metode penelitian yang digunakan adalah retrospektif, kemudian dianalisis secara deskriptif non analitik dengan mendeskripsikan atau melihat gambaran suatu keadaan secara obyektif. Langkahlangkah yang dilakukan meliputi pengumpulan data, klasifikasi pengolahan data, membuat kesimpulan dengan membandingkan ketentuan tertulis pada literatur.

\section{HASIL}

Berdasarkan hasil penelusuran data yang diperoleh dari total pasien yang pernah dirawat di Intensive Care Unit selama bulan Februari 2020 sebanyak 79 pasien. Pasien yang sesuai dengan kriteria inklusi sebanyak 68 pasien dan sisanya termasuk kriteria eksklusi, yaitu sebanyak 11 pasien 
yang hanya menerima satu macam sediaan obat parenteral IV. Data yang sudah diperoleh kemudian dianalisis secara deskriptif meliputi karakteristik pasien berdasarkan diagnosa dan usia pasien serta melihat gambaran kompatibilitas sediaan parenteral IV yang diberikan secara bersamaan pada pasien yang dirawat di Intensive Care Unit selama Februari 2020.

Hasil penelitian menunjukkan karakteristik pasien di ruang Intensive Care Unit yang mendapat terapi sediaan parenteral IV berdasarkan diagnosa dokter dan usia pasien. Kelompok diagnosa terbanyak adalah gagal napas dari berbagai kausa sebesar $41.18 \%$, sedangkan kelompok usia pasien terbanyak yang dirawat di Intensive Care Unit adalah usia $>65$ tahun sebesar $35.29 \%$. Gambaran kompatibilitas sediaan parenteral IV yang diberikan secara bersamaan diklasifikasikan sebagai inkompatibel (I) sebesar $3.72 \%$, kompatibel (K) sebesar $25.71 \%$, not clear (NC) sebesar $1.53 \%$ dan no recommendation (NR) sebesar $0.41 \%$. Hasil dari penelitian ini sebagian besar diklasifikasikan sebagai no information (NI) yaitu sebesar $68.64 \%$.

\section{PEMBAHASAN}

Berdasarkan Tabel 1, kelompok diagnosa terbanyak pasien yang dirawat di Intensive Care Unit adalah gagal napas dari berbagai kausa sebesar $41,18 \%$. Hal ini sama dengan hasil penelitian Hardisman (2008) dimana gagal napas merupakan diagnosa terbanyak setelah pasca bedah mayor pada pasien yang dirawat di Intensive Care Unit. Banyaknya kasus ini dimungkinkan karena gagal napas merupakan kelompok diagnosis yang dapat diakibatkan atau berasal dari berbagai penyakit primer lainnya. Penyebab tersering gagal napas diketahui dengan adanya insufusiensi pulmonal, hiperkapnia, dispnea, kemudian gangguan neurologis, penyakit jantung dan neuromuskuler. Dalam tatalaksana gagal napas, maka terapi terhadap penyebab (penyakit primer) harus dilakukan.

Gangguan kardiovaskuler dan sirkulasi merupakan diagnosa terbanyak kedua sebesar $32.25 \%$. Menurut WHO tahun 2015, 45\% kematian di dunia disebabkan oleh penyakit jantung dan pembuluh darah. Prevalensi penyakit jantung berdasarkan diagnosis dokter di Indonesia sebesar $1.5 \%$, dengan peringkat prevalensi tertinggi (Riskesdas, 2018).

Berdasarkan Tabel 2, dapat dilihat bahwa kategori usia terbanyak yang dirawat di ruang Intensive Care Unit RS Telogorejo Semarang periode Februari 2020 adalah kategori usia >65 tahun sebesar $35.29 \%$. Kategori usia terendah yaitu 17-25 tahun sebesar $1.47 \%$. Bertambahnya usia menyebabkan kondisi faal seseorang mulai menurun (Hakim, 2015).

$$
\text { Tabel } 3 \text { dan Gambar 1, }
$$
menunjukkan persentase data kompatibilitas campuran yang kompatibel sebesar $25.71 \%$. Sebanyak 691 dari 2688 pencampuran sediaan intravena yang diberikan secara bersamaan pada tempat campur additive, syringe, y site dinyatakan kompatibel menurut beberapa literatur yang digunakan sebagai acuan.

Hasil penelitian ini menunjukkan masih tingginya jumlah campuran sediaan parenteral yang masih belum memiliki informasi ketercampurannya (NI) yaitu sebesar $68.64 \%$. Ketiadaan informasi terkait kompatibilitas campuran pelarut dan senyawa obat IV pada penelitian ini sejalan dengan hasil kajian sistematis yang dilakukan oleh Kanji, et al. (2010). Selain itu, pada penelitian Dwijayanti, et al (2016) sebesar $30.16 \%$ campuran masih belum memiliki informasi ketercampurannya (NI). Hal ini dikarenakan, pada referensi tidak disebutkan secara jelas mengenai apakah campuran tersebut kompatibel atau inkompatibel, atau terdapat perbedaan kondisi pencampuran antara pengamatan aktual pada penelitian sebelumnya dengan informasi pada referensi. Campuran yang dikategorikan sebagai $\mathrm{NI}$ yang paling banyak ditemukan adalah campuran norepinephrine + steril water for injection pada tempat campur syringe. Campuran lainnya yang juga tidak memiliki informasi kompatibilitas adalah campuran yang dilakukan antara senyawa obat apa pun dengan produk perfusion solutions.

$$
\text { Selain campuran yang }
$$

diklasifikasikan $\mathrm{NI}$, ditemukan campuran yang diklasifikasikan sebagai NC sebesar $1.53 \%$. Pencampuran NC paling banyak adalah campuran antara Ringer lactat + ceftriaxone pada $y$ site sebesar $0.60 \%$. Dimasukkan dalam kategori NC karena terdapat perbedaan antara pengamatan 
aktual pada penelitian sebelumnya dengan informasi yang telah ada pada referensi.

Persentase kompatibilitas sediaan parenteral IV yang masuk kategori no recommendation (NR) sebanyak $0.41 \%$. Dikatakan NR apabila pada literatur tercantum informasi bahwa sebaiknya tidak dicampur dengan pelarut lain. Campuran sediaan parenteral IV yang masuk kategori NR paling banyak adalah sediaan vitamin neurotropik yang mengandung (Vitamin b1, b6, b12) dengan infus $\mathrm{NaCl} 0.9 \%$.

Kejadian inkompatibilitas potensial di ruang Intensive Care Unit sebesar 3.72\%, baik secara fisik maupun kimia. Inkompatibilitas secara potensial yaitu ketidakcampuran yang mungkin terjadi berdasarkan literatur yang meliputi inkompatibilitas secara fisik dan kimia. Pencampuran antara $\mathrm{NaCl} 0.9 \%$ dengan norepinephrine pada $y$ site menunjukkan $0.33 \%$ inkompatibel secara kimia yaitu terjadinya perubahan $\mathrm{pH}$. Hal ini dikarenakan adanya reaksi asam basa yang dapat mengubah $\mathrm{pH}$ serta kelarutan campuran. Akibat adanya molekul obat yang mengion (Anderson et al., 2014). Secara kimia campuran dikatakan inkompatibel jika campuran tersebut menghasilkan perubahan rata-rata dari pembacaan awal $\mathrm{pH} \leq 1$ selama periode pengamatan 120 menit (Housman et al., 2012).

Pencampuran antara Ringer lactat inkompatibilitas propofol menunjukkan yang dilakukan Valle et al. (2019), menunjukkan terjadinya endapan antara Ringer lactat dengan propofol pada simulasi $y$ site (Vallée et al., 2019). Proses pencampuran yang tidak tepat berpotensi menyebabkan pengendapan. Kadar obat terlarut berkurang dan menyebabkan tidak optimalnya terapi, sehingga dapat menyebabkan penurunan kualitas hidup pasien maupun mengancam jiwa (Lucida et al., 2014).

Ditemukannya inkompatibilitas potensial baik secara fisik maupun kimia dalam penelitian ini disebabkan karena risiko dari banyaknya sediaan intravena yang diberikan pada pasien yang dirawat di Intensive Care Unit secara bersama-sama dalam satu waktu. Perlunya suatu pengawasan dari seorang farmasis pada pencampuran sediaan intravena di rumah sakit merupakan salah satu langkah untuk mencegah adanya inkompatibilitas obat.

\section{KESIMPULAN}

Hasil penelitian menunjukkan karakteristik pasien di ruang Intensive Care Unit yang mendapat terapi sediaan parenteral IV berdasarkan diagnosa dokter dan usia pasien. Kelompok diagnosa terbanyak adalah gagal napas dari berbagai kausa sebesar $41.18 \%$, sedangkan kelompok usia pasien terbanyak yang dirawat di Intensive Care Unit adalah usia $>65$ tahun sebesar $35.29 \%$. Gambaran kompatibilitas sediaan parenteral IV yang diberikan secara bersamaan diklasifikasikan sebagai inkompatibel (I) sebesar $3.72 \%$, kompatibel (K) sebesar $25.71 \%$, not clear (NC) sebesar $1.53 \%$ dan no recommendation (NR) sebesar $0.41 \%$. Hasil dari penelitian ini sebagian besar diklasifikasikan sebagai no information (NI) yaitu sebesar $68.64 \%$.

\section{SARAN}

Perlunya dilakukan penelitian lanjutan terkait stabilitas fisik dan kimia pencampuran obat yang diklasifikasikan sebagai NI, NC dan NR, sebagai upaya penjaminan kualitas pelayanan kesehatan yang berdampak pada keselamatan pasien (patient safety). Selain itu, perlunya mempertimbangkanbesarnya pencampuran yang tidak diketahui informasinya, pemantauan kondisi pasien dan kadar obat dalam darah perlu dilakukan sebagai upaya dalam pelakasanaan budaya patient safety di rumah sakit.

\section{UCAPAN TERIMA KASIH}

Penulis hendak menghaturkan terimakasih kepada Ibu Dr. apt. Maria Caecilia Nanny S.H., M.Sc dan Ibu apt. Erna Prasetya Ningrum, M.Sc., yang telah membimbing jalannya penelitian ini serta lbu apt. Ebta Narasukma, M.Sc., dan Ibu apt. Yustisia Dian Advistasari, M.Sc., yang telah membantu mengkritisi hasil penelitian ini.

\section{DAFTAR PUSTAKA}

Anderson, C., Boehme, S., Oullette, J., Stidham, C., MacKay, M. 2014. Physical and Chemical Compatibility of Injectable Acetominophen during Simulated Y-Sitte Administration. Hosp-Pharm.49.

Departemen Kesehatan RI. 2009. Pedoman Pencampuran Obat Suntik dan Penanganan Sediaan Sitostatika. Jakarta: Depkes RI. 
Dwijayanti, S., Irawati, S., Setiawan, E. 2016. Profil Kompatibilitas Sediaan Obat Intravena dengan Pelarut pada Pasien Intensive Care Unit. Jurnal Farmasi Klinik Indonesia.5.(2):83 - 97

Fahimi, F., Ariapanah, P., Faizi, M., Shafaghi, B., Namdar, R., Ardakani, M.T. 2008. Errors in Preparation and Administration of Intravenous Medications in The Intensive Care Unit of Teaching Hospital: An Observational Study. Aust Crit Care. 21(2).

Hakim L. 2015. Farmakokinetik Klinik. Edisi 2. Yogyakarta: Bursa IImu.

Housman, S., R, Tessier., Pamela., Nicolau., David, P., Kuti., Joseph, L. 2012. Physical Compatibility of Telavancin Hydrochloride with Select IV Drugs during Simulated Y-site Administration. American Journal of Health-System Pharmacy.

Kanji, S., Lam, J., Goddard, R.D., Johanson, C., Singh, A, Petrin, L. 2013. Inappropriate Medication Administration Practices in Canadian Adult ICU: a Multicenter, CrossSectional Observational Study. Ann Pharmacother.47.
Lucida, H., Armal, K., Harefa., Suradi, M. 2014. Kajian Kompatibilitas Sediaan Rekonstitusi Parenteral dan Pencampuran Sediaan Intravena pada Tiga Rumah Sakit Pemerintah di Sumatera Barat. Prosiding Seminar.

RCN. 2010. Standards for Infusion Therapy Edtion. London: Royal College of Nursing.

Riskesdas. 2018. Hasil Utama Riset Kesehatan Dasar. Kementerian Kesehatan Republik Indonesia.

Surahman, E., Mandalas, E. and Kardinah, E. I. 2008. Evaluasi Penggunaan Sediaan. Majalah IImu Kefarmasian, $\mathrm{V}(1)$ : 21-39.

Vallée, M., Barthélémy, I., Friciu, M., Pelletier, É., Forest, J.M., Benoit, F., Leclair, G. 2019. Compatibility of Lactated Ringer's Injection With 94 Selected Intravenous Drugs During Simulated Y-site Administration. Hospital Pharmacy. 
Lampiran

Tabel 1

Distribusi Pasien yang Dirawat di Intensive Care Unit Periode 2020 Berdasarkan Kelompok Diagnosa Penyakit

\begin{tabular}{cccc}
\hline No & Kelompok Diagnosa & $\mathbf{N}$ & $\%$ \\
\hline 1 & Pasca bedah mayor & 6 & $8.82 \%$ \\
2 & Gagal napas, dari berbagai kausa & 28 & $41.18 \%$ \\
3 & Penurunan kesadaran & 1 & $1.47 \%$ \\
4 & Gangguan kardiovaskuler dan sirkulasi & 22 & $32.35 \%$ \\
5 & Lain-lain & 11 & $16.18 \%$ \\
\hline & Total & $\mathbf{6 8}$ & $\mathbf{1 0 0 . 0 0 \%}$ \\
\hline
\end{tabular}

Tabel 2

Distribusi Pasien yang Dirawat di Intensive Care Unit Periode 2020 Berdasarkan Usia

\begin{tabular}{clcc}
\hline No & Kategori Usia & $\mathbf{N}$ & $\%$ \\
\hline 1 & $17-25$ tahun & 1 & $1.47 \%$ \\
2 & $26-35$ tahun & 3 & $4.41 \%$ \\
3 & $36-45$ tahun & 3 & $4.41 \%$ \\
4 & $46-55$ tahun & 20 & $29.41 \%$ \\
5 & $56-65$ tahun & 17 & $25.00 \%$ \\
6 & $>65$ tahun & 24 & $35.29 \%$ \\
\hline & Total & $\mathbf{6 8}$ & $\mathbf{1 0 0 . 0 0 \%}$ \\
\hline
\end{tabular}

Tabel 3

Data Kompatibilitas Sediaan Parenteral IV Pasien yang Dirawat di Intensive Care Unit Periode Februari 2020

\begin{tabular}{clcc}
\hline No & \multicolumn{1}{c}{ Kompatibilitas Obat } & $\mathbf{N}$ & $\%$ \\
\hline 1 & Inkompatibel & 100 & $3.72 \%$ \\
2 & Kompatibel & 691 & $25.71 \%$ \\
3 & Not clear (NC) & 41 & $1.53 \%$ \\
4 & No information (NI) & 1845 & $68.64 \%$ \\
5 & No recommendation (NR) & 11 & $0.41 \%$ \\
\hline & Total & $\mathbf{2 6 8 8}$ & $\mathbf{1 0 0 . 0 0 \%}$ \\
\hline
\end{tabular}




\section{Gambar :}

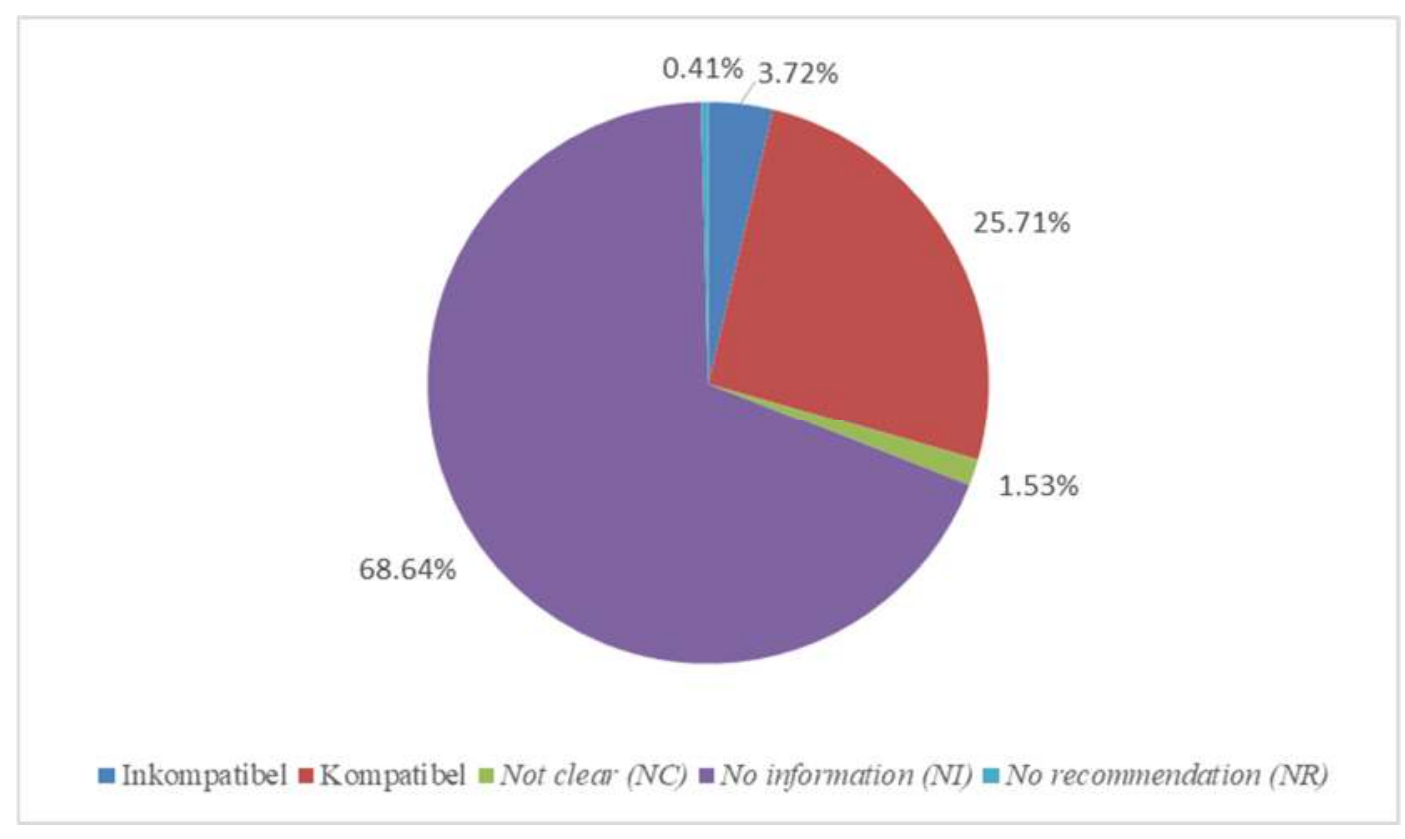

Gambar 1. Data Kompatibilitas Sediaan Parenteral IV Pasien yang Dirawat di Intensive Care Unit Periode Februari 2020 